Marijan Lipovac

\title{
ČEH DUH, PRVI ZAGREBAČKI BISKUP
}

Marijan Lipovac

Ured za odnose s javnošću i medije

Hrvatska akademija znanosti i umjetnosti

Zagreb

\author{
UDK 272-722.52Duh(497.521.2Zagreb)"10/11" \\ 272-722(497.521.2Zagreb)"10/11"(091) \\ 327(497.5:437.3) \\ Izlaganje sa skupa \\ Primljeno: 9.5.2018. \\ Prihvaćeno: 1.6.2020. \\ DOI: https://dx.doi.org/10.21857/mjrl3u75q9
}

\begin{abstract}
O prvom zagrebačkom biskupu, Čehu Duhu, u povijesnim izvorima postoje vrlo oskudni podaci. Ne zna se kada i gdje je rođen i umro i koliko dugo je u Zagrebu obnašao biskupsku službu, no povjesničari i filolozi ipak su pokušali rekonstruirati njegovo podrijetlo. Tako su stvorene hipoteze da je Duh bio češki benediktinac, iz glagoljaškog samostana u Sázavi ili latinskog samostana u Břevnovu kraj Praga, ili pak redovnik nekog glagoljaškog samostana na području panonske Hrvatske, rodom iz sela Čehi kraj Zagreba. Biskupu Duhu u zasluge se ubraja početak izgradnje zagrebačke katedrale, donošenje najstarijih do danas sačuvanih knjiga u Zagreb te nastanak glosa na hrvatskom jeziku u Radonovoj Bibliji. lako je u povijesnom sjećanju dugo bio potisnut i imao drugorazrednu ulogu u odnosu na osnivača Zagrebačke biskupije kralja Ladislava, u posljednjih desetak godina biskup Duh kao osoba s kojom počinju hrvatsko-češki odnosi i nazočnost Čeha na području Hrvatske postaje sve poznatiji zahvaljujući češkoj manjini i Hrvatsko-češkom društvu. U Zagrebu je 2005. dobio stube sa svojim imenom, a 2014. spomenik u Dubravi kraj Vrbovca.
\end{abstract}

Ključne riječi: biskup Duh, kralj Ladislav, Zagrebačka biskupija, hrvatsko-češki odnosi, povijest Zagreba

Za razliku od osnivača Zagrebačke biskupije kralja Ladislava koji je u povijesti stekao neizbrisivo ime te je čak proglašen i svetim, prvi zagrebački biskup koji je nosio neobično ime Duh ostao je uglavnom potisnut u povijesnom pamćenju, iako se radi o važnoj osobi s kojom počinje pisana povijest Zagreba i njegove biskupije, kao i povijest hrvatsko-čeških odnosa. Razlog su prije svega oskudni povijesni izvori jer jedini pouzdani podatak koji nam o prvom zagrebačkom biskupu donosi povelja ostrogonskog nadbiskupa Felicijana iz 1134. je taj da se zvao Duh (u latinskom obliku Duch), da je po narodnosti bio Čeh i da je bio sposoban muž časna života. 
Nije poznato kada i gdje je Duh rođen ni gdje i kada je umro, odnosno do kada je obnašao dužnost zagrebačkog biskupa, kao niti tko ga je i gdje zaredio za biskupa. Nepoznata je i godina osnutka biskupije, no povjesničari ju smještaju u razdoblje između 1090. i 1094. Duh vjerojatno nije dugo obnašao biskupsku službu jer prvi kaptolski kroničar, gorički arhiđakon Ivan, 1334. kao drugog biskupa spominje Bartolomeja za kojeg kaže da je biskupovao još za života kralja Ladislava, a on je umro 1095. ${ }^{1}$

Iako se ne zna ništa o Duhovu podrijetlu, osim da je bio Čeh, povjesničari su ga ipak pokušali rekonstruirati stvorivši nekoliko teorija o tome zašto je baš jedan Čeh došao za biskupa na hrvatsko područje. Glavni motiv tih teorija bilo je pitanje je li liturgijski jezik Zagrebačke biskupije bio latinski ili slavenski pa slijedom toga je li Duh bio pripadnik latinskog ili slavenskog obreda. Istraživači su prihvatili nepotvrđenu tezu da je Duh bio benediktinac pa su s obzirom na pripadnost jednom od dvaju bogoslužja pokušali otkriti iz kojeg je samostana potjecao.

Prave rasprave o tome je li liturgija Zagrebačke biskupije u početku bila latinska ili slavenska, odnosno je li Duh bio glagoljaš ili latinaš počele su sredinom 19. stoljeća. Slavensku teoriju najsustavnije je razradio Ivan Tkalčić koji se prvi pozabavio i pitanjem podrijetla biskupa Duha. O toj temi pisao je u više prigoda, a najopsežnije 1904. u djelu Slavensko bogoslužje u Hrvatskoj. On spominje mišljenje mađarskog povjesničara Viktora Récseija da je Duh bio redovnik najstarijeg mađarskog benediktinskog samostana Pannonhalme, a zatim postavlja tezu da je Duh onamo došao iz glagoljaškog samostana u Sázavi kraj Praga. Samostan je 1036. utemeljio češki knez Břetislav I., kao sjedište slavenskog bogoslužja koje je time obnovljeno u češkim zemljama stoljeće i pol nakon progona učenika svetih Ćirila i Metoda. Kad je Břetislav I. umro, njegov nasljednik Spytyhněv II. 1056. progoni benediktince-glagoljaše iz Sázave te oni odlaze u Ugarsku. Kad je knez Spytyhněv 1061. umro, njegov nasljednik Vratislav II. pozvao je opata Vida i glagoljaše iz Ugarske koji su se vratili u Sázavu, gdje su ostali do 1096. (prema starijim podacima do 1092.) kad je Břetislav II. ukinuo samostan i definitivno prognao posljednje češke glagoljaše. Tkalčić je smatrao da je Duh bio jedan od redovnika iz Sázave koji su nakon progona 1056. našli utočište u Ugarskoj, a ako ne tada onda 1092., te da je stoga bio glagoljaš, a prva liturgija zagrebačke biskupije slavenska. ${ }^{2}$

Tkalčić je smatrao da su razlozi da se uvede slavensko bogoslužje u novoj biskupiji i za biskupa postavi glagoljaš bili političke naravi. On tvrdi da je Ladislav znao da je njegov šogor Zvonimir bio ubijen "što je nehajan bio da zapriječi progon slavenskog bogoslužja". Stoga je, smatra Tkalčić, radi učvršćenja nećaka Almoša kao nametnutog hrvatskog kralja za zagrebačkog biskupa imenovao svećenika koji se služio slavenskim jezikom u bogoslužju. U prilog svojoj tezi Tkalčić ističe podatak iz Felicijanove isprave da su Duhu za pomoćnike dodijeljeni svećenici iz zaladske i

Andrija Lukinović, Zagreb - devetstoljetna biskupija, Zagreb 1995., str. 20.

2 Marijan Lipovac, Biskup Duh, Zagreb 2006., str. 18-19. 
somođske županije, gdje se sredinom 9. stoljeća nalazio centar kneževine slavenskog kneza Kocelja. ${ }^{3}$

Istu argumentaciju koristi i publicist Juraj Ćuk 1932. koji kaže da je u 11. stoljeću u panonskoj Hrvatskoj bilo rašireno slavensko bogoslužje, a da Ladislavu nije bila namjera izmijeniti liturgijski jezik jer se to ne bi uklapalo u njegovu politiku da na miran način dođe do hrvatskog prijestolja. Ćuk donosi svoju argumentaciju zašto je upravo jedan Čeh imenovan prvim zagrebačkim biskupom, a za pomoćnike svećenici iz mađarskih županija. Po njegovu mišljenju, Ladislav nije imao povjerenja u domaće svećenstvo pa je morao dovesti strance. Ćuk daje i dodatnu argumentaciju, a to je postojanje sela Čehi nadomak Zagreba koje su očito osnovali neki češki doseljenici. $^{4}$

S njim je u vezi i druga teorija o Duhovu porijeklu, koju je 1994. postavio lingvist Valentin Putanec, a prema kojoj je Duh bio glagoljaš i Čeh, ali ne iz Češke nego iz sela Čehi koje su možda osnovali glagoljaši prognani iz Velike Moravske. Prema toj teoriji Duh bi bio pripadnik nekog glagoljaškog samostana na području panonske Hrvatske. Putanec spominje i još jedan argument u prilog tezi da je Duh bio glagoljaš - tvrdi da je običaj na ugarskom dvoru bio da dvorski kapelani budu imenovani za biskupe, pa je tako bio slučaj s kasnijim zagrebačkim biskupima Francikom i Singidinom. Budući da se u izvorima ne spominje nikakav dvorski kapelan imenom Duh, ili Spiritus, to je prema Putanecu dokaz da Duh nije bio svećenik latinskog nego slavenskog obreda. ${ }^{5}$

Danas u historiografiji prevladava mišljenje da je liturgijski jezik u Zagrebačkoj biskupiji od početka bio latinski i da je sukladno tome i Duh bio svećenik latinskog obreda. Prvi je tu tezu sustavno obradio 1910. Svetozar Ritig istaknuvši da je Ladislav Zagrebačku biskupiju osnovao kako bi bila dio ugarske crkve koja je od početaka liturgijom bila latinska, a da mu osnivanje biskupije sa slavenskim jezikom nikako nije moglo ulaziti u političke planove jer bi ona bila strana crkvenom organizmu njegove države. Ritig navodi praktičan razlog zašto je Duh postavljen za biskupa: kao Čeh lakše se mogao sporazumijevati sa svojim vjernicima. ${ }^{6}$

Slavensku tezu najbolje je 1925. pobio Franjo Fancev, istodobno dokazujući latinsku tezu analizom najstarijih zagrebačkih liturgijskih knjiga. Fancev se slaže s mišljenjem da je na području Zagrebačke biskupije bilo slavenskog bogoslužja, no upravo to smatra i glavnim crkvenim razlogom njenog osnutka. Naime, u Felicijanovoj povelji kaže se da je Ladislav biskupiju osnovao kako bi biskupova briga na put istine privela one koje je bludnja idolopoklonstva otuđila od štovanja Boga. Takva

\footnotetext{
Ivan Tkalčić, Slavensko bogoslužje u Hrvatskoj, Zagreb 1904., str. 72.

Juraj Ćuk, Povijest Zagreba do 1350, Garešnica 1932., str. 22-23.

5 Valentin Putanec, Tri priloga za proučavanje prvog doba postanka zagrebačke biskupije, Zagrebačka biskupija i Zagreb 1094-1994., str. 122.

6 Svetozar Ritig, Povijest i pravo slovenštine u crkvenom bogoslužju, sa osobitim obzirom na Hrvatsku, Zagreb 1910., str 64 .
} 
formulacija mogla bi značiti da je područje nove biskupije bilo vjerski zapušteno i s tragovima poganstva, no Fancev podsjeća da se u 10. i 11. stoljeću slavensko bogoslužje nazivalo heretičnim kako bi se našao i dogmatski razlog za njegovu zabranu. Stoga zaključuje da je Zagrebačka biskupija od početka imala latinsko bogoslužje kako bi se time suzbilo slavensko te da Duh nikako nije mogao biti glagoljaš jer bi to značilo da širi tobožnju herezu koju je trebalo suzbiti. Osim toga, Ladislavov cilj bio je Slavoniju politički vezati uz Ugarsku pa je i crkvena hijerarhija morala biti pouzdana i zavisna od ugarske, što u slučaju da je Duh glagoljaš ne bi bio slučaj.

Fancev se doduše ne protivi mišljenju da je Duh potjecao iz Sázave, ali smatra da se u tom slučaju morao odreći glagoljaštva i prihvatiti latinski obred jer u suprotnom ne bi postao zagrebački biskup.

No Fancev postavlja svoju teoriju o Duhovu podrijetlu i nagađa da je on mogao biti član najstarijeg češkog samostana, u Břevnovu kraj Praga (danas dio grada), kojeg je 993. osnovao praški biskup sveti Vojtjeh.

Ladislav je naime s tim samostanom održavao veze pa je jednom o njemu izjavio da je "prebivalište izuzetne svetosti u Češkoj, u kojem brojno mnoštvo redovnika živi životom svetaca". Argument svojoj tezi o Duhovu podrijetlu iz Břevnova Fancev nalazi i u analizi benediktinskog sakramentara iz Metropolitanske knjižnice, za koji utvrđuje da je pisan krajem 11. stoljeća za neki samostan posvećen svetoj Margareti. Danas se smatra da se radi o samostanu svete Margarete de Hahót kod Samogyvara, no Fancev smatra da bi to mogao biti i samostan u Břevnovu jer je i on bio, i danas je, posvećen svetoj Margareti. U tom slučaju moguće je da je Duh iz Břevnova došao u Hahót, a od tamo u Zagreb. ${ }^{7}$

Ovdje je zanimljivo istaknuti svetu Margaretu, kojoj su posvećena dva moguća Duhova samostana, budući da je i župna crkva u Dubravi kod Vrbovca, koju je Duh dobio kao svoj posjed, posvećena toj svetici pa ne treba isključiti da je Duh donio njen kult. Možda je s Duhom vezana i nekadašnja crkva svete Margarete u Zagrebu, današnja pravoslavna crkva, po kojoj ime nosi Margaretska ulica.

Teza o Duhovom porijeklu iz Břevnova bi mogla biti točna ne samo stoga jer je Ladislav s tim samostanom održavao veze, nego stoga jer su iz Břevnova potjecali redovnici prvog ugarskog benediktinskog samostana Pannonhalme osnovanog 997., a Anastazije, prvi opat tog samostana, ranije je bio opat samostana u Břevnovu, da bi 998. postao prvi ugarski nadbiskup, sa sjedištem u Kalocsi ili Ostrogonu. Ne bi stoga trebalo biti neobično da je kralj Ladislav i za prvog zagrebačkog biskupa doveo redovnika iz češkog samostana koji je već stotinjak godina ranije odigrao važnu ulogu u uvođenju kršćanstva u Ugarskoj. ${ }^{8}$

Franjo Fancev, O najstarijem bogoslužju u Posavskoj Hrvatskoj, Zbornik kralja Tomislava, Zagreb 1925., str. 513-536.

8 Lipovac, Biskup Duh, str. 37. 
Kao prvom zagrebačkom biskupu, Duhu su u zasluge pripisivana mnoga djela i prvenstvo u mnogo toga, međutim uvijek se radi o pretpostavkama za koje nema čvrstih dokaza u povijesnim izvorima. No u svakom slučaju dolazak prvog biskupa u Zagreb morao je imati velik utjecaj na razvoj ne samo vjerskog nego i kulturnog života tako da te pretpostavke nisu neutemeljene. Osnovno što se pripisuje Duhu je početak gradnje katedrale, koja je posvećena tek 1217., jer je kao biskup morao u svom sjedištu imati svoju stolnu crkvu, bilo neku postojeću ili sagraditi novu. ${ }^{9}$

Smatra se da je Duh donio sa sobom u Zagreb najstarije kodekse koji se čuvaju u Metropolitanskoj knjižnici - već spomenuti Sakramentarij svete Margarete, pisan između 1082. do 1092. za benediktinsku opatiju Sv. Margarete de Hahòt kod Samogyvara, Pontifikalni obrednik pisan za đurskog biskupa Chartwirga u 11. stoljeću te Benedikcional, pisan za Ostrogonsku nadbiskupiju. ${ }^{10}$

Međutim, za hrvatsku kulturu i pismenost najznačajnije djelo koje se pripisuje Duhu jesu glose u Radonovoj Bibliji koje bi mogle biti najstariji spomenik hrvatskog jezika. Spomenuta Biblija pisana je krajem 8. ili početkom 9. stoljeća za opatiju Saint Vaast u Arrasu u Francuskoj, nakon čega su ju benediktinci u 11. stoljeću donijeli u Ugarsku, zatim je došla u Zagreb, a od 1576. nalazi se u Beču. Njen dolazak u Zagreb također se veže uz biskupa Duha, kao i za ranije spomenute knjige. Biblija je za slavistiku zanimljiva stoga što je iznad latinskih riječi, između redaka i sa strane, zabilježena 71 glosa, tj. zabilješka, pisana latinicom na nekom od slavenskih jezika. Vatroslav Jagić je 1903. ustvrdio da je to češki sa staroslavenskim elementima, ali da ima i hrvatskih utjecaja te da je stoga autor Hrvat-glagoljaš koji je živio u Češkoj. Dragutin Kniewald je 1940. prvi postavio teoriju da je autor glosa sam biskup Duh, a njegovu teoriju prihvatio je i detaljno razradio Josip Hamm 1952. On je najprije ustvrdio da su glose napisane na hrvatskom tlu, a da je osnovni fond riječi hrvatski, dok su bohemizmi (prefiks roz- umjesto raz-, modlit umjesto moliti) usputni, što dokazuje da je glose pisao Čeh. Ako je autor glosa Duh, vjerojatno mu je netko od domaćih ljudi diktirao, odnosno prevodio s latinskog, a kod pisanja nehotično je Duhu tu i tamo umjesto hrvatskog pobjegao češki oblik. ${ }^{11}$ Budući da se najstariji spomenik hrvatskog jezika, Baččanska ploča, uobičajeno datira s godinom 1100., u slučaju da je autor glosa upravo Duh, one bi bile starije od Baščanske ploče za nekoliko godina i bile bi najstariji spomenik hrvatskog jezika uopće.

Ni navedene hipoteze nisu bile dovoljne da se biskup Duh u 19. ili 20. stoljeću pretvori u povijesni mit, kao što je primjerice bio slučaj s Grgurom Ninskim o kojem također nema odviše podataka. U historiografiji se Duh uglavnom spominje usputno, a nešto detaljnije u znanstvenim i stručnim radovima. Ponekad se pogrešno navodi da je bio Slovak, iako Felicijanova povelja jasno kaže da je Duh bio "boemus", tj.

\footnotetext{
Isto, str. 43.

10 Isto, str. 29.

11 Josip Hamm, Glose u Radonovoj bibliji, Slovo, br. 1, Zagreb 1952, str. 19-31.
} 
Čeh. Na starom i današnjem oltaru svetog Ladislava u katedrali prikazan je i biskup Duh, ali u odnosu na sveca kojem je oltar posvećen ipak ima drugorazrednu ulogu. U svojoj domovini Češkoj Duh je ostao nepoznat, no zanimljivo je da ga pjesnik Jan Kollár spominje u svom spjevu Kći Slave iz 1832., smjestivši ga u raj u društvo svetih Ćirila i Metoda i drugih osoba značajnih za pokrštenje slavenskih naroda koji su "vodili naš narod Gospodinu u krilo". U popratnim objašnjenjima Kollár je za Duha napisao da je bio "rodom Čeh, apostol Hrvata" (rozený Čech, blahozvěst Kroatiu). ${ }^{12}$ Sintagma "apostol Hrvata" međutim kod Hrvata nije nikad zaživjela kao atribut za biskupa Duha.

U zadnjih desetak godina biskup Duh je poznatiji u javnosti jer ga popularizira češka manjina, koja ga smatra svojim rodonačelnikom, i Hrvatsko-češko društvo na čiji prijedlog je Duh 2005. dobio stube sa svojim imenom, između Opatovine i Tkalčićeve ulice. To je bio poticaj da se stube između Dolca i Tkalčićeve ulice 2007. imenuju po kralju Ladislavu. U Dubravi kraj Vrbovca Duh je 2014. dobio i svoj spomenik, tako da ta zagonetna osoba iz najranije zagrebačke povijesti ipak polako dobiva zasluženo mjesto u općoj kulturi i kolektivnom pamćenju, barem u Zagrebu i okolici.

12 Marijan Lipovac, "Apostol Hrvata" imat će prvi spomenik u Dubravi, Susreti - glasilo Hrvatsko-češkog društva, br. 32, 2014., str. 18-19. 


\title{
Marijan Lipovac
}

\section{A Czech called Duh, the First Bishop of Zagreb}

\begin{abstract}
Summary
On the first bishop of Zagreb, there are only meagre historical data. The charter of Archbishop Felician of 1134 mentions that he was called Duh, that he was Czech by origin and that he was capable man of honourable life. It is not known where Duh was born nor where and when he died, that is, until when he held the duty of the bishop of Zagreb. Historians and philologists tried go reconstruct what was his origin and constructed Povjesničari i filolozi su ipak pokušali rekonstruirati njegovo porijeklo pa su stvtheories that he was a Benedictine monk of the Czech Glagolytic monastery of Sázava or from the Latin monastery of Brevnovu near Prague, or that he was a monk of some Glagolytic monastery from the area of Northern Croatia, who was by origin from the village of Čehi near Zagreb.

The reason why the king of Hungary brought exactly a Czech for the bishop of the newly established diocese in the conquered Croatian area was probably linguistic proximity with the congregation. According to the tradition, exactly Duh brought in Zagreb the oldest extant ecclesiastical books, and the glossa in the Radon's Bible which may be the oldest monument of Croatian language are also attributed to him, as well as merits for beginning of the construction of the Zagreb cathedral. In his native homeland, Bohemia, Duh remained mostly unknown, but poet Jan Kollár mentioned him in his poem Slávy Dcera [The daughter of Sláva] of 1832, placing him in the Paradise among men important for the Christianisation of Slavonic peoples, and in an explanation, he called Duh "the Apostle of the Croats". Members of the Czech minority consider Bishop Duh as their founder. In Zagreb, one public stairs were named upon Bishop Duh, and in 2014 a monument to him was erected in Dubrava near Vrbovec.
\end{abstract}

Key words: Bishop Duh, King Ladislas, the bishopric of Zagreb, Croato-Czech relations, history of Zagreb 
